\title{
Extra- and intra-cellular lipases from a thermophilic Rhizopus oryzae and factors affecting their production
}

\begin{abstract}
A thermophilic Rhizopus oryzae was isolated, and parameters affecting its production of extra- and intra-cellular lipases were investigated. All carbon sources tested with the exception of sucrose generally inhibited the production of extracellular lipase, but enhanced the production of intracellular lipase. Peptone was the best substrate for extracellular enzyme production, but for intracellular lipase production other substrates such as tryptone, tryptic soy digest, polypeptone, and corn steep liquor gave comparable results. Among lipid substrates, glycerol was the only stimulator of extracellular enzyme production, whereas olive oil, triolein, and oleic acid had very positive effects on intracellular enzyme production. Shaking enhanced the production of both types of enzymes; the temperature optima were 45 and $37^{\circ} \mathrm{C}$ for extra- and intra-cellular lipases, respectively. A pH of 5.0 was optimal for production of both enzymes.
\end{abstract}

Keyword: Lipases; Production; Rhizopus oryzae 